\section{IMMUNE SYSTEMS}

Factors Regulating the Immune Response

Report of a WHO Scientific Group. (World Health Organization Technical Report Series, No. 448.) Pp. 88. (WHO: Geneva, 1970.) 10s; \$1.75; Sw.fr.5.

A PANel of wise men was assembled by the World Health Organization in Geneva on September 1-6, 1969. This report is a distilled version of their deliberations. It is easily the bargain of the year for immunologists. The presentation is somewhat didactic, but this is probably an advantage; to have dotted all the i's and crossed all the t's would have extended the booklet tediously.

The first five chapters define the immunological apparatus and the basic variables in immune responses. Current theories of cellular immunology are enunciated concisely and in a readable manner. The next two chapters are concerned with intrinsic regulatory factors in primary and secondary immune responses. A chapter follows which is largely devoted to the effect that extrinsic regulators may have on the course of immunity. The last chapter is grandly named "How Does the Entire Immune System Becomo and Remain Functional ?". In a way this chapter heading epitomizes the comprehensiveness of the book. It is a most remarkable production which should be required reading for all those interested in current developments in immunology.

It is perhaps sad that a booklet of only eighty-eight pages takes a year to produce and it is unfortunate that points of fact in the text may not easily be traced (except by the expert who knows, anyway) to specific entries in the abbreviated reference lists which relate to each subject. These are minor flaws and the members and secretariat of the group of scientists involved are to be congratulated on a first-class piece of work.

A. J. S. Davies

\section{VETERINARIAN IMMUNOLOGY}

\section{Veterinary Immunology}

By W. J. Herbert. Pp. xi $+356+22$ plates. (Blackwell (Scientific): Oxford and Edinburgh, 1970.) 85s.

Immunology transcends the boundaries of scientific disciplines gaining in stature as it draws upon the resources of each. It has emerged from its historical association with microbial infections, from the days when immunity was first recognized, to become an all-embracing science attracting followers from most sections of the scientific community. Therein lies its strength and dynamism and the explanation for its recent dramatic transformation.

For these reasons it is desirable that textbooks of immunology should be written specifically for definitive groups of students and others, whose need for knowledge of the subject was once thought to be subsidiary or peripheral to their chief objectives. Such books should be designed to introduce these large numbers of undergraduates and graduates to a fuller understanding of fundamental and updated immunological concepts. Hopefully then, individual interest, enthusiasm and participation may follow, and gaps in our understanding of many diverse aspects of the subject be filled. One such specific group is the veterinary profession many of whose members have been actively participating in the development of immunology during its emergence as a subject.

In this book Dr Herbert has succeeded in producing a text that is well orientated to the requirements of veterinary undergraduates and practising veterinary surgeons, as well as being of benefit to those biologists interested in immunological responses of the various species of domesticated animals. Fundamental physiological mechanisms, theories of antibody production, descriptions of diagnostic serological tests, and physicochemical techniques for characterization of immunoglobulins are necessarily similar whether one is dealing with humans or animals. There is, nevertheless, considerable diverse data recorded in this book on the various species of domesticated animal, and sufficient examples of clinical disease states, the diagnosis and prevention of which are dependent on immunological methods, to make it an extremely valuable aid to the student of veterinary science and medicine. Good veterinary examples of allergy and atopy are perhaps rather lacking, but this is no fault of the author; indeed, he makes specifie reference to these gaps in our knowledge of veterinary allergic conditions.

The diagrams, figures and photographs are clearly reproduced and well chosen to illustrate the text. They introduce the reader, in a concise and clear manner, to the subject, giving him a sound grasp of the various concepts of antigen-antibody reactions. Details of molecular configurations, spatial arrangement and steric hindrance are wisely left for the enquiring reader to consult texts of immunochemistry; indeed, such readers are provided with suggestions for further reading. Some errors creep into most textbooks and this book is no exception. In a rapidly expanding subject it is, however, difficult to be precise and the author does well to maintain elarity in an eminently instructive book with wide appeal to students of veterinary and biological science alike.

\section{Allan}

\section{FISH OF COLD CLIMES}

\section{Biology of Coregonid Fishes}

Edited by C. C. Lindsey and C. S. Woods. (Proceedings of an International Symposium held in Winnipeg, Canada, August 25-29, 1969.) Pp.560. (University of Manitoba: Winnipeg, 1970.) \$8.

THE coregonid fishes are a dominant group in cold freshwaters of the northern hemisphere. They are distributed across the northern Eurasian and North American land masses and limited at the southern extreme of their range to mountainous regions, as in the British Isles and the Alps. Especially in inland areas they are valuable commercially. Perhaps because of their wide distribution and fisheries value they have attracted the attention of many workers, yet they still remain a difficult and elusive group to ichthyologists.

This volume comprises thirty-five papers read to an International Symposium on Biology of Coregonid Fishes held in 1969 . It has been reproduced photographically from typewritten contributions, with the result that it was available only eleven months after the symposium meetings and at a remarkably low price. The editors, Dr C. C. Lindsey and Dr C. S. Woods, are to be congratulated on this considerable achievement.

The coregonid fishes thrive in regions which have been repeatedly and recently disrupted by glaciation, and they have acquired variable body forms and plastic life styles that challenge conventional classification. It is understandable therefore that most of this volume is devoted to studies bearing on the classification or systematics of the group. The remaining papers cover a variety of subjects including parasitology, ecological aspects, reproductive biology and fisheries topics.

Coregonid systematics are certainly involved, but with recent advances in their study, particularly the use of protein properties, a clearer picture is emerging. Given such a plastic group, with populations often living in isolation in lakes, with the introduction of exotic forms, and introgression within lakes also taking place, descriptive systematics has become very complex. Populations have been described as species, or subspecies, until nobody could see the wood for the trees. Present trends, however, are towards systematic rationalization, with many fewer spccies, and the recognition that phenotypic variants do not require names. 